\title{
The relationship between plant density and survival to water stress in seedlings of a legume tree
}

\author{
Eliane Akiko Honda ${ }^{1 *}$ (D), Natashi Aparecida Lima Pilon² (1) and Giselda Durigan ${ }^{1,2}$ (1)
}

Received: December 13, 2018

Accepted: April 23, 2019

\begin{abstract}
Competition for soil water is one of the major processes that drive the assembly of plant communities, particularly in regions subjected to long dry seasons. The relationship between plant density and soil water competition has strong, but poorly understood, practical implications for population dynamics, restoration and conservation. We planted seedlings of the pioneer legume tree Senegalia polyphylla in containers and assessed the effects of plant density on their resistance to water stress. We completely eliminated the above-ground parts (stem and shoots) of randomly selected plants at 60 -days post-planting in order to create three different densities of seedlings. We saturated the soil of the remaining seedlings and then deprived them of additional water until all seedlings died. We assessed the time elapsed from water suppression to wilting and death of individual plants. We found a strong negative relationship between plant density and time to wilting or death. Seedlings survived water stress $80 \%$ longer when density was reduced by two-thirds. Planting in lower densities or reducing density by thinning should be considered as strategies to enhance resistance to water stress in drought-prone regions.
\end{abstract}

Keywords: drought stress, evapotranspiration, management, plant competition, Senegalia polyphylla, soil water, thinning

Competition for soil water is one of the major processes driving the assembly of plant communities (Assis et al. 2011), particularly in regions subjected to long dry seasons, where mortality can be high due to water stress (Allen \& Breshears 1998; Fensham et al. 2009). If availability of a resource is limited by environmental conditions, competition will be more severe the higher the density of individuals sharing that resource. The lower the density, the more resource will be available for each individual (Aussenac \& Granier 1988; Bucci et al. 2008; Zou et al. 2008; Campo et al. 2014) and, therefore, growth rates and probability of survival tend to be higher (Meinzer et al. 1996). Under environmental conditions where soil water is a scarce resource, plant growth and survival depend on adaptations to low water availability (McDowell et al. 2008). This dependence has implications for both natural ecosystems and plantations. The challenge is, therefore, to match plant water uptake to limited water availability. Reducing plant density in this way can minimise the effects of climatological drought and neutralise soil drought (Falkenmark \& Rockstrom 2008).

1 Laboratório de Ecologia e Hidrologia Florestal, Floresta Estadual de Assis, Instituto Florestal, 19802-300, Assis, SP, Brazil

2 Instituto de Biologia, Universidade Estadual de Campinas, 13083-872, Campinas, SP, Brazil

* Corresponding author: eahonda@gmail.com 
Plant density is not, however, the only factor that influences competition for water. Water uptake by plant communities is related to their above-ground biomass (Simonin et al. 2007; Bucci et al. 2008; Zou et al. 2008; Caterina et al. 2013), which increases over time up to a maximum level dictated by the environmental carrying capacity (Forrester et al. 2010). Since biomass increment over time in tree plantations is influenced by initial density, closer spacing results in higher carbon fixation rates (Toillon et al. 2013; Hakamada et al. 2017). Where water is scarce, however, the greater water uptake promoted by denser stands can lead to early exhaustion of available water, which, in turn, leads to decreased productivity or even death of the most sensitive individuals or species in the stand (Meinzer et al. 1996). Quantifying plant competition for soil water, therefore, is important not only for physiological plant ecologists, but also for ecological applications, such as ecological restoration and conservation management. Knowing the relationship between planting density and the community response to soil water competition can be an important tool to aid restoration planning and to support management decisions.

Our goal was to quantify the effects of planting density on early-stage plant resistance to water stress. We conducted an experiment under controlled environmental conditions, with seedlings of the tree Senegalia polyphylla planted at different densities and with the same water availability. We tested the hypothesis that water competition would cause plants to die earlier with denser planting.

The experiment was carried out at the Laboratory of Forest Ecology and Hydrology, Assis State Forest, São Paulo, Brazil, starting in November 2008 (spring) and extending up to April 2009 (autumn), corresponding to the period with the historically (Sentelhas et al. 2003) highest rainfall (mean monthly rainfall $146 \mathrm{~mm}$ ), air temperature (mean monthly temperature $24^{\circ} \mathrm{C}$ ) and therefore high relative humidity in the region. The species used in this study, Senegalia polyphylla (DC.) Britton \& Rose (Fabaceae-Papilionoideae), is a fastgrowing evergreen pioneer tree species, widely distributed across the Neotropics and occurring in different ecosystems, with the majority of occurrences recorded in savannas (Cerrado), dry (Caatinga) and moist forests (Atlantic Forest) (CRIA 2019). Such ecological plasticity has made this species one among those most frequently included in restoration projects for savannas and forests. For the experiment, we collected seeds from a single population near the study site (forest-savanna transition) in an attempt to find genetically homogeneous material. Seedlings were produced in a nursery, by direct seeding and later transfer to plastic bags with substrate composed of $3 / 4$ subsoil and $1 / 4$ organic matter. After 40 days post sowing, we selected 45 seedlings of similar height (about $7 \mathrm{~cm}$ ) that were transplanted into three containers.

The containers were made of iron plates, with dimensions of $40 \mathrm{~cm} \mathrm{x} 60 \mathrm{~cm}$ and a depth of $35 \mathrm{~cm}$, with an opening in the upper part for allowing lateral flow of surplus surface water and a lower opening for drainage of percolated water. The three containers were installed in the open under similar environmental conditions on wooden stands $80 \mathrm{~cm}$ above ground, slightly inclined to avoid accumulation of water in the bottom. Each container was filled with a 5-cm-thick layer of gravel, which was covered with a geotextile filter to separate it from the soil. The remainder of the volume was completed with a mixture of subsoil and organic matter in the ratio of 5:1. The containers were filled with the substrate to the edge of the upper drainage opening, and irrigated for three consecutive days, before planting the seedlings.

In each container, we planted 15 seedlings of Senegalia polyphylla in three lines of five plants, regularly distributed (Fig. 1A). The seedlings developed in the open, receiving rainwater or being irrigated in periods without rain. Because we had only three containers to carry out the experiment, we assessed the homogeneity of plants before treatment application to reduce possible effects of pseudoreplication. We measured all seedlings in each container 60 days after planting. All seedlings survived and the average height, around $40 \mathrm{~cm}$, did not differ among containers (ANOVA, $\mathrm{F}=1.11, \mathrm{P}=0.339)$. We then randomised treatment application among the containers. Treatments to represent
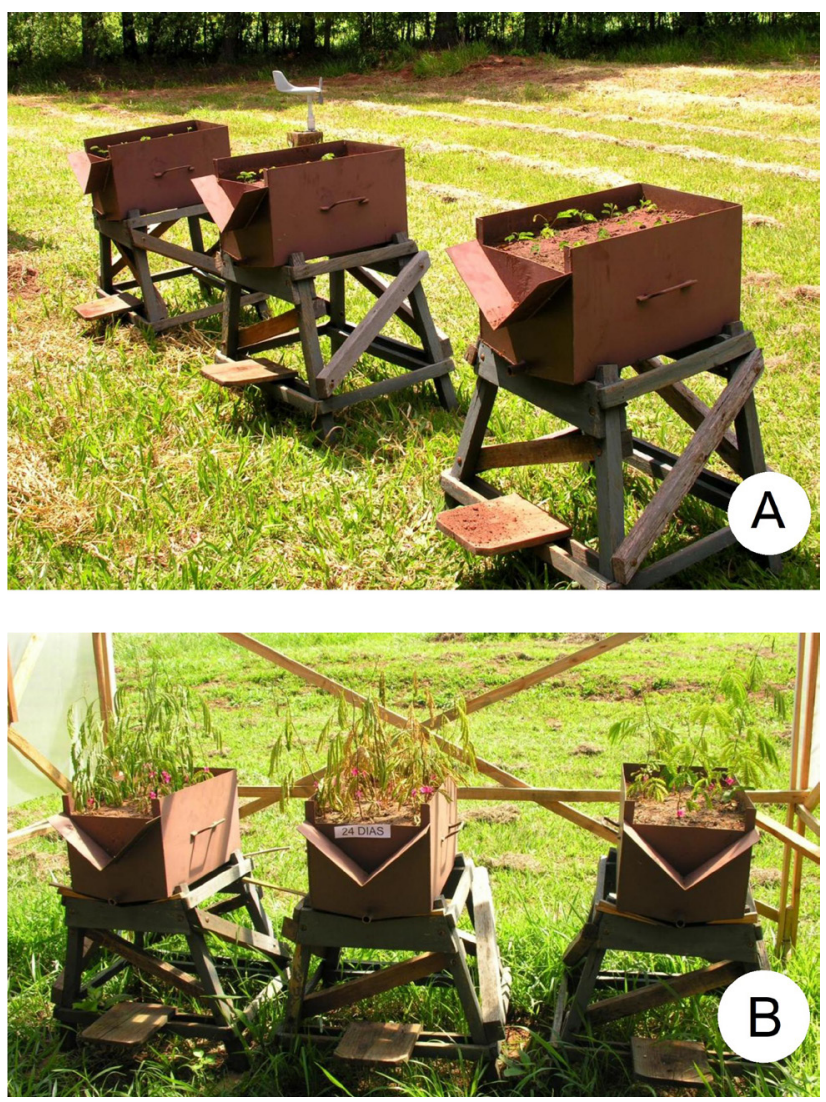

Figure 1. Containers just after planting 15 seedlings each (A), and 24 days after treatments application and water suppression (B). On the left, density 2D (container with 10 seedlings), center 3D (15 seedlings), and right 1D (five seedlings). 
different densities were: $\mathrm{D}$ (five plants per container), 2D (10 plants) and 3D (keeping all 15 plants). Within treatments D and 2D, we eliminated randomly chosen plants to obtain the proper density. We measured the remaining seedlings and again the average height did not differ among treatments in the beginning of the observation period $(40 \mathrm{~cm}$ in $\mathrm{D}, 41$ $\mathrm{cm}$ in $2 \mathrm{D}$ and $38 \mathrm{~cm}$ in $3 \mathrm{D}$ ) (ANOVA, $\mathrm{F}=1.15, \mathrm{P}=0.332$ ). We dried the eliminated seedlings to a constant weight and we found an average dry above-ground biomass of $4.5 \mathrm{~g}$ per plant. Assuming that plant size was homogeneous, we estimated the initial dry biomass at $63 \mathrm{~g} \mathrm{~m}^{-2}$ in treatment $\mathrm{D}$, $125 \mathrm{~g} \mathrm{~m}^{-2}$ in treatment 2D, and $188 \mathrm{~g} \mathrm{~m}^{-2}$ in treatment 3D.

After treatment application, seedlings remaining in the three containers were irrigated until soil saturation. Thus, the amount of water available per container was the same in all treatments. After saturating the soil, a transparent plastic cover was erected over the containers to prevent rain from entering them. Rain water exclusion was maintained until the end of the experiment.

Each seedling was numbered with a plastic label (Fig. 1B) and leaf water status was visually evaluated daily (Engelbrecht et al. 2007). The first symptom of drought stress was leaflet closure during the hottest period of the day (wilting) and a plant was considered dead when the aerial parts were completely dry. Time (days) to wilting and to death after water suppression was recorded for each individual.

Average time (days) from soil saturation to seedling wilting or death was compared among treatments by permutational analysis of variance (PERMANOVA), using the aovp function from package lmPerm (Wheeler 2010), followed by post hoc Tukey's HSD. This is a robust alternative to analyse data sets with few replicates, absence of normality or pseudoreplication (Legendre \& Legendre 1998). The P-value was obtained after 10000 permutations of the original data, at a significance level of $5 \%$. We used the $R$ environment ( $R$ Development Core Team 2016) for all analyses.

The average time elapsed from water suppression to the wilting point differed among the highest and the lowest densities $(\mathrm{df}=2$, Inter $=10000, \mathrm{P}=0.003)$. Wilting started, on average, after nine days in the treatment 3D, after 12 days in 2D and after 16 days in D (Fig. 2A).

Time elapsed since water suppression to seedling death followed the same results observed for wilting, differing between the highest (3D) and the lowest (D) plant density $(\mathrm{df}=2$, Inter $=10000, \mathrm{P}=0.007)$. On average, seedlings died after 42 days without water input in treatment 3D, after 61 days in treatment 2D, and after 76 days in treatment $D$ (Fig. 2B). By reducing density to $1 / 3$, seedlings took $78 \%$ longer to show signs of wilting and $81 \%$ longer to die.

Despite the limited sample size, we encourage the use of our approach in other studies, preferably with more replicates, to provide clear information for applied plant ecology. Because we did not have true replicates of the containers, we carefully checked if conditions for plant growth were similar among the three containers before applying the treatments and checked again after the treatments were randomized. We believe that pseudoreplication effects were thus minimized in our study.

Our results demonstrate that Senegalia polyphylla seedlings are drought hardy, but that increased planting density reduces water availability and, therefore, the plants die earlier than they would at lower densities. Independently of density, time elapsed from the last water input until death was 5 -fold longer than time taken for water competition to start (wilting), indicating that $S$. polyphylla can survive for long periods with low leaf water potential (Engelbrecht et al. 2007). Given that the main regions of occurrence of S. polyphylla (Seasonal Atlantic Forest, Cerrado and

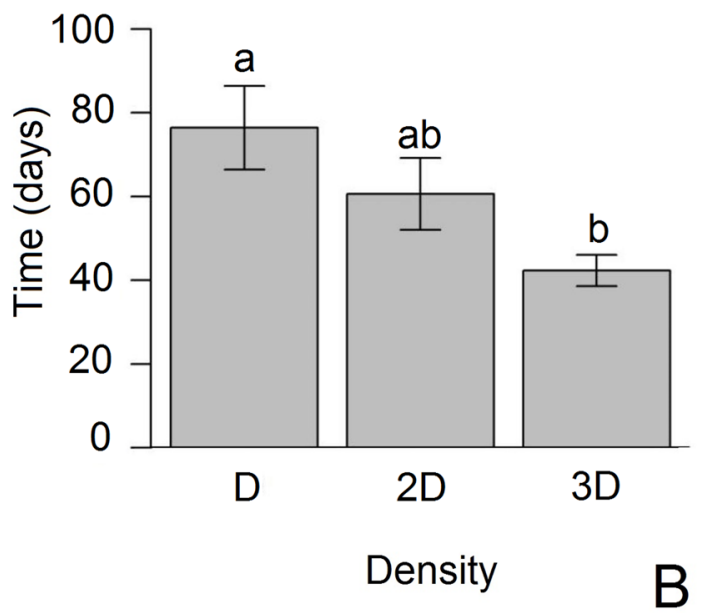

Figure 2. (A) Comparison of the average time (days) from water suppression to the wilting point of seedlings of Senegalia polyphylla planted at different densities. (B) Comparison of the average time (days) from water suppression to death of seedlings of Senegalia polyphylla planted at different densities ( $\mathrm{D}=5$ seedlings, $2 \mathrm{D}=10$ seedlings and $3 \mathrm{D}=15$ seedlings). For both graphs, treatments followed by the same letter do not differ by the Tukey's test $(\alpha=5 \%)$ and bars represent the standard error. 
Caatinga) experience a dry season that can last from one to ten months (IBGE 1978), long survival of seedlings under water limitation is likely to be an adaptation of this species to its environment.

The influence of density was equally strong for either wilting or death of seedlings of Senegalia polyphylla under water limitation, with time elapsed to wilting or death increasing by $78 \%$ and $81 \%$, respectively, as density was reduced to $1 / 3$ of the initial. In general, in the absence of water limitation, water consumption is approximately proportional to leaf mass (Bucci et al. 2008; Toillon et al. 2013, Campo et al. 2014). On the other hand, studies have shown that transpiration intensity of a leaf decreases as vegetation cover increases (Meinzer et al. 1996). The transpiration curve of a plant population, therefore, often reaches a plateau when transpiration is measured as a function of density (Larcher 1995; Bucci et al. 2008). Leaf wilting is the most widely used indicator of plant drought stress (Engelbrecht et al. 2007). However, species with early leaf wilting are not always the first to succumb to drought when multiple species are evaluated, since the responses to water stress vary among species (McDowell et al. 2008). In our study, however, since all individuals belonged to the same species, origin, age and size, we did not expect other factors than density to influence their survival to water stress.

Seedlings are more sensitive to negative soil water potentials than are adult trees, due to the small volume of soil explored by the incipient root system (McDowell et al. 2008). Additionally, their small size limits water storage to a smaller volume with which to buffer water stress (Goldstein et al. 1998). Under conditions of the present study, soil depth was only $35 \mathrm{~cm}$ and all possible avenues of water entry into the system (rain and capillarity) were excluded. In natural environments, it is expected that different densities lead to different responses to water availability and that plants predisposed to water stress will use strategies to access more water through morphological, anatomical and physiological adaptations (McDowell et al. 2008).

Some studies have demonstrated that greater density could decrease the evaporative losses of individual plants (Meinzer et al. 1996; Medhurst et al. 2002). In our study, under controlled conditions, the same amount of water was shared by plants at variable densities, resulting in lower volume of individual evaporative loss at higher densities. That resulted in seedlings of Senegalia polyphylla dying earlier when at higher density, indicating that water available per individual was depleted earlier via transpiration, as observed by Irvine et al. (2004). Decreasing plant density in the present study, therefore, resulted in longer retention of available soil water, and consequently, a longer survival time. Although the methodological limitations of our study do not allow direct inferences for natural conditions, similar results were obtained under field conditions in a study with different planting densities of Acacia koa, 26 months after planting (Meinzer et al. 1996). Other studies also have demonstrated the effects of decreasing plant density, including higher resilience to drought events (Sohn et al. 2016) and higher long-term productivity (Irvine et al. 2004). The results of all these studies have important implications for the trajectory of forest communities throughout the successional process, for ecological-restoration planning and adaptive management of planted and native forests in regions subjected to long periods of water deficit (Bradford \& Bell 2017; Gleason et al. 2017; Jump et al. 2017). Future studies, based upon robust experiments, under controlled and field conditions, and encompassing different species and plant functional groups, could bring relevant contributions to reinforce our findings and allow extrapolation to natural conditions.

Senegalia polyphylla seedlings presented a remarkable capacity to survive under competition for water. This is likely among the explanations for the high ecological plasticity (adaptation to distinct biomes) and broad geographic occurrence of this species. The density of seedlings had a large influence on the length of time droughted seedlings survived: the higher the density, the higher the probability of all individuals dying in a drought. The effect on survival of manipulating density was strong, indicating that changing density by management strategies can bring about large gains in plant longevity under water limitation.

\section{Acknowledgements}

We thank S.W. Flake for carefully revising the content and English grammar of the manuscript, and D.S. Dias for preparing the figures in their final version. This research was supported by Fundação de Amparo à Pesquisa do Estado de São Paulo - FAPESP (scholarship grant \#2014/05573-1) and Conselho Nacional de Desenvolvimento Científico e Tecnológico - CNPq (productivity grant \#303179/2016-3).

\section{References}

Allen CA, Breshears DD. 1998. Drought-induced shift of a forest-woodland ecotone: rapid landscape response to climate variation. Proceedings of National Academy of Sciences USA 95: 14839-14842.

Assis ACC, Coelho RM, Pinheiro ES, Durigan G. 2011. Water availability determines physiognomic gradient in an area of low-fertility soils under Cerrado vegetation. Plant Ecology 212: 1135-1147.

Aussenac G, Granier A. 1988. Effects of thinning on water stress and growth in Douglas-fir. Canadian Journal of Forest Research 18: 100-105.

Bradford JB, Bell DM. 2017. A window of opportunity for climate-change adaptation: easing tree mortality by reducing forest basal area. Frontiers in Ecology and the Environment 15: 11-17.

Bucci SJ, Scholz FG, Goldstein G et al. 2008. Controls on stand transpiration and soil water utilization along a tree density gradient in a Neotropical savanna. Agricultural and Forest Meteorology 148: 839-849.

Campo AD, Fernandes TJ, Molina AJ. 2014. Hydrology-oriented (adaptive) silviculture in a semiarid pine plantation: How much can be modified the water cycle through forest management? European Journal of Forest Research 133: 879-894. 
Caterina GL, Will RE, Turton DJ, Wilson DS, Zou CB. 2013. Water use of Juniperus virginiana trees encroached into mesic prairies in Oklahoma, USA. Ecohydrology 7: 1124-1134.

CRIA - Centro de Referência em Informação Ambiental. 2019. SpeciesLink. http://www.splink.org.br. 4 Jan. 2019.

Engelbrecht BMJ, Tyree MT, Kursar TA. 2007. Visual assessment of wilting as a measure of leaf water potential and seedling drought survival. Journal of Tropical Ecology 23: 497-500.

Falkenmark M, Rockström J. 2008. Building resilience to drought in desertification-prone savannas in Sub-Saharan Africa: The water perspective. Natural Resources Forum 32: 93-102.

Fensham RJ, Fairfax RJ, Ward DP. 2009. Drought-induced tree death in savanna. Global Change Biology 15: 380-387.

Forrester DI, Collopy JJ, Morris JD. 2010. Transpiration along an age series of Eucalyptus globulus plantations in southeastern Australia. Forest Ecology and Management 259: 1754-1760.

Gleason KE, Bradford JB, Bottero A, et al. 2017. Competition amplifies drought stress in forests across broad climatic and compositional gradients. Ecosphere 8(7): e01849. doi: 10.1002/ecs2.1849

Goldstein G, Andrade JL, Meinzer FC, et al. 1998. Stem water storage and diurnal patterns of water use in tropical forest canopy trees. Plant Cell and Environment 21: 397-406.

Hakamada R, Hubbard RM, Ferraz S, Stape JL, Lemos C. 2017. Biomass production and potential water stress increase with planting density in four highly productive clonal Eucalyptus genotypes. Southern Forests 79: 251-257.

IBGE - Instituto Brasileiro de Geografia e Estatística. 1978. Mapa Brasil Climas. Rio de Janeiro, IBGE.

Irvine J, Law BE, Kurpius MR, Anthoni PM, Moore D, Schwarz PA. 2004. Age-related changes in ecosystem structure and function and effects on water and carbon exchange in ponderosa pine. Tree Physiology 24: 753-763.

Jump AS, Ruiz-Benito P, Greenwood S et al. 2017. Structural overshoot of tree growth with climate variability and the global spectrum of drought-induced forest dieback. Global Change Biology 23: 37423757.
Larcher W. 1995. Physiological plant ecology. 3rd. edn. New York, Springer. Legendre P, Legendre L. 1998. Numerical ecology. 2nd. edn. Amsterdam, Elsevier.

McDowell N, Pockman WT, Allen CD, et al. 2008. Mechanisms of plant survival and mortality during drought: why do some plants survive while others succumb to drought? New Phytologist 178: 719-739.

Medhurst JL, Battaglia M, Beadle CL. 2002. Measured and predicted changes in tree and stand water use following high-intensity thinning of an 8-year-old Eucalyptus nitens plantation. Tree Physiology 22: 775-784.

Meinzer FC, Fownes JH, Harrington RA. 1996. Growth indices and stomatal control of transpiration in Acacia koa stands planted at different densities. Tree Physiology 16: 607-615.

R Development Core Team. 2016. R: A language and environment for statistical computing. Vienna, R Foundation for Statistical Computing.

Sentelhas PC, Marin FR, Ferreira AS, Sá EJS. 2003. Banco de dados climáticos do Brasil. http://www.bdclima.cnpm.embrapa.br. 04 Feb. 2018.

Simonin K, Kolb TE, Montes-Helu M, Koch GW. 2007. The influence of thinning on components of stand water balance in a ponderosa pine forest stand during and after extreme drought. Agricultural and Forest Meteorology 143: 266-276.

Sohn JA, Hartig F, Kohler M, Huss J, Bauhus J. 2016. Heavy and frequent thinning promotes drought adaptation in Pinus sylvestris forests. Ecological Applications 26: 2190-2205.

Toillon J, Fichot R, Dallé E, Berthelot A, Brignolas F, Marron N. 2013. Planting density affects growth and water-use efficiency depending on site in Populus deltoides $\times$ P. nigra. Forest Ecology and Management 304: 345-354.

Wheeler RE. 2010. multResp() lmPerm. The R project for statistical computing. http://www.r-project.org/.

Zou CB, Breshears DD, Newman BD, Wilcox BP, Gard MO, Rich PM. 2008. Soil water dynamics under low-versus high-ponderosa pine tree density: ecohydrological functioning and restoration implications. Ecohydrology 1: 309-315. 